\title{
Social Distance in Safaricom Chattitude Dating Cartoon Advertisement
}

*Dr. Yakub Adams

\author{
*Corresponding author, Department of Linguistics, Maseno University, Kenya; yakubdms@yahoo.co.uk
}

\section{Ms. Jackline Okello}

Department of Linguistics, Maseno University, Kenya; jackyokelo@yahoo.com

\section{Doi:10.5901/ajis.2015.v4n3p207}

\section{Abstract}

This study closely looks at the Safaricom Chattitude advertisement for any form of representation of the social variation exhibited therein. Language use tends to establish specific social group uniqueness. Certain unique terms would include culturally specific vocabulary, context sensitive topics and shared attitudes. It is more than likely then that an advertisement would influence the consumer by defining 'reality' in a way that would make him or her respond positively to the product. The purpose of this article is to use an animated advertisement to demonstrate how social distance and proximity is reflected in verbal, and in indirect or paralinguistic communication. The study adopted an analytical research design domiciled within the qualitative methods and employed a hybrid version of Social Identity Theory in the process of analysing data.

Keywords: Chattitude, Social Distance, Proximity, Identity

\section{Cartoon Use in Communicative Forms}

Taylor (2012) posits that in today's society, the quality and the usefulness of multimedia, especially cartoon animation has gone beyond just entertainment. Animation can be seen in television commercials, ads, software/video games, infomercials and cinemas worldwide. This technological advancement to society has provided an alternative to sharing information to society in a more appealing way than traditional methods of human interaction.

Business communication is only effective when it actually reaches the target audience and delivers the message. Cartoons can be a powerful tool for doing that: they are different, their graphics attract the eye and the humour they use helps readers and viewers to retain their content (www.grantland.net/sitelist.htm - 18-06-2014). Callcott and Lee (1994) proposed that using animated characters as modes of communication can attract the attention of most consumers. In addition, using what Callcott and Lee (1994) call virtual spokes-characters (cartoon caricatures) will in most cases give the market brand its selling image.

It can be noted that these cartoon caricatures normally demonstrate positive behaviour and hardly any negative characteristics. Therefore, as posited by Garretson and Niedrich (2004) more and more advertising firms and businesses have developed their own cartoon caricatures, for instance Safaricom company, the focus of the present study. Furthermore, the diverse facial caricatures of the brand images also produce different consumer perceptions and believability of the product. It is noted that the use of human-like males and cartoon-like females bring more confidence to consumers than cartoon-like males and human-like females (Luo, Peter, Susan, and Kathleen, 2006). However, Neeley and Schumann (2004) assert that spokes-characters with both voices and actions can possibly have a lasting impression on customers and subsequently impact on their decision making.

Such lasting impressions would lead to strong attitude changes within the target audience as well as the attitude towards the advertisement itself (Petty and Cacioppo, 1986). These drawn conclusions may show that a successful advertising cartoon caricature would affect advertisement effectiveness by being attractive, credible and attitude changing. According to Luo et al. (2006), previous research on cartoon caricatures in various forms of advertising look into the facial appearance and gender of characters and equally confirm the significance of spokes-characters on the advertisement impact.

In the Kenyan scenario, lots of cartoon caricatures have gained currency. The cartoon usage is vastly noted in the world of entertainment such as music and animated movies. There are famous animated programmes well liked across all ages. The focus of this article is to demonstrate cartoon usage effectiveness in ascertaining pertinent human issues. 


\section{Language and Advertisement}

According to Krauss and Chiu (1998), language provides ways by which the society is viewed. Language is noted to be the way cultural knowledge is passed on and how people within the society comprehend issues during various forms of interaction. Krauss and Chiu (1998) add that language is comprehended in issues concerned with, among others, attitude change, social perception, personal identity, social interaction, intergroup bias and stereotyping attribution. They add that language is basically the medium by which people's responses are sought and hence it plays a role in both stimulus and response.

Krauss and Chiu (1998) further deliberate that just as language impacts on people's social life, the elements of social life themselves dictate the manner by which language is used in diverse communicative arenas. These authors add that linguists regard language as an abstract structure that exists independently of specific instances of usage and that any communicative exchange is situated in a social context that has effect on the linguistic variants interlocutors use. It is noteworthy to posit that how interactants in a social situation perceive what others know, think and believe and their attitudes towards their own situations will mostly affect what Krauss and Chiu (1998) call the form and content of their acts of speaking.

Language use that establishes social group uniqueness as an aspect of social identity is described in terms of culturally specific vocabulary, context sensitive topics and shared attitudes (Krauss and Chiu, 1998). As Krauss and Chiu (1998) aver, it is more than likely then that an advertisement would influence the consumer by determining how he or she would respond in relation to the displayed product and own cosumer needs. An advertisement also socializes the consumer into thinking that he or she can buy a way of life as well as goods (Krauss and Chiu, 1998). It can be argued that prolonged experience of advertising and other commercial texts contribute to shaping peoples' identities as consumers.

Advertising is not merely business expenditure for moving merchandise but a vast array of symbols and ideas that are an integral part of modern culture (Leiss, Kline and Jhally, 1986). Advertising has been linked to religion, modern showmanship, and patriotic goals in wartime and popular culture. An advertiser's intention is to give meaning to a product by developing associations in the mind of the reader or listener and persuading them to buy it. These associations are cultural in the sense that any member of the culture for which the advertisement is produced will find them easy to recognize. It is important to understand the concept of advertising in ways that would assist both the advertiser and the audience to achieve successful communication.

Dyer (1982) posits that an advertisement is a message that is aimed at persuading target audiences to purchase particular products, endorse an organization or accept a particular idea or view. In addition, just as McDonald (1992) observes, advertisements are all around us: in our daily newspapers, magazines, on hoardings in the street, on buses and assailing us from the radios, televisions and the cinema. Each of these means of advertising has what the advertiser relies on most for effective communication.

This article aims to investigate how distance and proximity is reflected in verbal, and more specifically, indirect communication. The aspect of speech creating both physical and emotional space between two interlocutors becomes the main point of discussion in this paper. An interesting question, though, may be whether there is any connection between nonverbal space and space created by speech. A study conducted by the cultural psychologists Stephan, Liberman and Trope (2010) who combine theories from psychology with the politeness theories of Brown and Levinson (1987) investigated space, social distance and proximity. These studies posit that personal space refers to the immediate space a person exudes, for instance, how far a speaker is standing from the hearer during a conversation. Territory, on the other hand, makes reference toefers to what space a person may claim and defend against other possible claimants, such as for instance, what a person communicates when he puts up a fence around his property. In this present study, the interest will also lie in what the two participants accentuate in their attempt at forging a relationship. The concepts of modernity as demonstrated by social media chatting and attitude of diverse social classes become evident in the present study.

Concerning spatial distance, Brown and Levinson (1987) found in one study that people speaking in a polite language stood further apart from the hearer than when they spoke in a colloquial language. They added that when the target person of a written text was unknown or spatially distant, such as for instance an unknown student in another building, the degree of formality or politeness in that text increased.

The answer, therefore, is in the presence of the diversity of the same language in a speech community which is technically referred to as social class dialects. From the assessments by Brown and Levinson (1987) there are certain linguistic differences between the speech of two or more speakers in communicative events which belie their unique 
social background differences. Brown and Levinson (1987) add that these differences would probably be phonetic and phonological differences which are normally referred to as social-class accents. Hence, language clearly reflects and impacts on the differences within diverse human societies. Subsequently, it is expected that different social groups use unique social dialects and as experienced members of those particular speech communities. We may note parallels between the development of these social varieties and the development of regional varieties: in both cases barriers and distance appear to be relevant. This study closely looked at the Safaricom Chattitude advertisement for any form of representation of the social variation exhibited therein.

\section{Social Identity Theory}

Stets and Burke (2000) state that in Social Identity Theory (SIT), the self is reflexive in that it can take itself as an object and can categorize, classify or name itself in particular ways in relation to other social categories or classifications. This process that Stets and Burke (2000) refer to is called self-categorization by Turner, Hogg, Oakes, Reicher and Wetherell (1987) with close reference to the SIT from which forms of identities are realized. In relation to the process of selfcategorization, Hogg and Abrams (1988) aver that a social identity is a person's knowledge of membership to a social category or group. Individuals would therefore create and cement their social identities by interacting with fellow group members.

Moreover, Hogg and Abrams (1988) ascertain that in this theoretical framework, a social group encompasses a set of individuals who view themselves as members of the same social category. Hogg and Abrams (1988) further assert that through a social comparison process, persons who are similar to the self are categorized with the self and are labeled the in-group while those who differ from the self are categorized as the out-group. In this article the concept of in-group and out-group features are inherent.

Hogg and Abrams (1988) also make clear the concept of social categories. These categories, in which individuals place themselves, are parts of a structured society and exist only in relation to other categories where each has more or less power, prestige, status and so on. Further, Hogg and Abrams (1988) point out that the social categories precede individuals and those individuals are born into an already structured society. Once in society, people derive their identity or sense of self largely from the social categories to which they belong.

Furthermore, Turner et al. (1987) point out that much of SIT focuses on relations that emanate from relationships within intergroup interactions. This refers to how people come to see themselves in-group interactants in comparison with members of the out-group and the consequences of this categorization such as ethnocentrism (Turner et al., 1987). Turner et al. also state that having a particular social identity means being at one with a certain group, being like others in the group and seeing things from the group's perspective. In contrast, having a particular role identity means acting to fulfill the expectations of the role, coordinating and negotiating interaction with role partners and manipulating the environment to control the resources for which the role has responsibility (Stets \& Burke, 2000).

Borrowing from Bruner (1957), Oakes (1987), asserts that salience is a product of accessibility and fit. Oakes (1987) posits that acceessibility is the readiness of a given category to become an entity obviously viewed in the person while fit is the congruence between the stored category specifications and perceptions of the situation. Therefore, in SIT, salience determines the situational activation of an identity within specific social set-ups and situations. Oakes (1987) concludes that a particular identity becomes activated and salient as a function of the interaction between the characteristics of the perceiver (accessibility) and of the situation (fit).

\section{Research Methodology}

The purpose of this article is about how social distance and proximity is reflected in verbal, and in indirect or paralinguistic communication. The study hence adopted an analytical research design domiciled within the qualitative methods. This is an in depth study design associated mainly with qualitative research, answering the questions why, how, when and by whom thus providing suitable reasons (Kumar, 2011). Wayne and Stuart (2004) assert that analytical research use already available facts or information and analyze these to make a critical evaluation of the data. Accordingly, this study used data obtained from a Safaricom cartoon advertisement to provide primary data to be analyzed to make a critical and in-depth evaluation of this paper's objective. The Safaricom Chattitude advertisement was purposively sampled and represented both the study population and the study sample size. This was purely library based research which heavily borrowed from readily available literature in this field and researchers competence in sociolinguistics. 


\title{
5. Data Analysis and Discussion
}

This Safaricom advertisement is based on the sale of data bundles for chatting with friends and acquaintances over the internet. It is portrayed as enabling easy communication by people within popular social media sites such as Facebook, Twitter and WhatsApp. Safaricom has based this sales advertisement from a point of view of blind dating services meant to bring single people together. This study will, therefore, focus more on the activities during the dating session than the raw concept of advertisement. The dating pair is Masgwembe, the gentleman and Msupaa the lady. The subthemes are noted forthwith.

\subsection{Social Class Categories}

Levin and Lin (1988) put it that speakers from different social categories are likely to impose their unique ethnic speech styles and display speech convergence in order to reduce the psychological distance between themselves and others. Levin and Lin (1988) however, add that speakers may likewise react to identity-threatening circumstances by ensuring their own individuality is clearly enhanced to show out-group members their uniqueness. This is clearly demonstrated right from the onset of the conversation between the dating couple.

\section{Transcript 1:}

\begin{abstract}
Masgwembe: So what do you do for a living? Me na do job kwa gym (I work in a fitness gym). Kulainisha hizo ma biceps na ma...(I do work on the biceps...) (Demonstrates for her by stretching off the chair)

Msupa: (Interrupts Masgwembe) Sorry...um ...let me reply to this WhatsApp. (pointing at her phone)

Masgwembe: So what do you like doing for fun?

Msupa: Uh...oh...Faceboooking. Do you know what Facebook is? (Masgwembe seems surprised at the question) Yeah...tut...I don't think you do.
\end{abstract}

In this transcript, Msupaa seems not to be paying any attention to what Masgwembe is saying and even physically demonstrating. According to Krauss and Chiu (1998), Speech-accompanying gestures are usually regarded as forms of communication whose function is to enance or underscore information conveyed in the spoken discourse. Masgwembe, being a well built man, imagined he would impress Msupa with his well toned biceps, a product of spending most of his time in the gym. This attempt fails to even draw an appreciation from Msupa. Masgwembe attempts to create familiarity between himself and Msupa by codeswitching. This is seen in his 'Me na do job kwa gym' explanation. The codeswtching may also be an indication that he has deficiencies in English and Kiswahili. His attempt at creating convergence fails.

She instead interrupts Masgwembe who was intent in providing details of his gym exploits. She also gestures to Masgwembe that she was busy replying to a message from WhatsApp in her phone. From the foregoing, it is quite clear that Msupa is not attracted to Masgwembe's supposed well toned body. She is focused on her chit chats on the social media platform. The conversation is an illustration of a case of divergence of interests. The transcript confirms what Bourhis and Giles (1977) had found that language use also can demonstrate one's social identity and affirm intergroup distinction. Msupa is intent on maintaining her distinct attitude and class category which is not in the league of Masgwembe's exploits. This is further confirmed by Masgwembe's seeming frustration at what exactly Msupa does for fun hence the question: 'So what do you like doing for fun?'. The question shows Masgwembe's perception of fum which seems far removed from just chatting online on phone. He seems not to approve of online chatting which discourages real traditional chatting. transcript:

Msupa's determination to maintain her social space is similarly revealeded by her sarcasm in the following

\section{Transcript 2:}

Masgwembe to Msupa: So where do you live?

Msupa: Heaveeen. (sarcastically)

Masgwembe: So are you single? Ama? (or what?)

Msupa: I really need to do this

The response Msupa gives that she lives in 'Heaveeen', is an answer to frustrate Masgwembe's efforts. This is supposed to be a date but it seems not to be going well for Masgwembe. He really is trying to know the lady and hence attempts to narrow the social distance by asking such personal questions but Msupa is determined to maintain her status. It is without that Msupa is not interested in him. She ignores Masgwembe's question about her marital status by replying 
that 'I really need to do this' which means that she was busy chatting on her phone with other like minded online acquaintances. This affirms Hogg and Abrams' (1988) assertion that a social group is a set of individuals who hold a common social identification or look at themselves as members of the same social group. Msupa is more comfortable with her online chat friends than with Masgwembe who seems not to be in her social media framework. They cannot then be compatible.

Masgwembe's frustration is evident from her reaction to the response Msupa gives in the transcript below:

Transcript 3:

Masgwembe to Msupa: Eh...where do you go to school?

Msupa: Um..haha...Let me...

Masgwembe: 00ooh!

Msupa is not really paying attention to what Masgwembe is asking and it makes him feel really frustrated and subsequently seems to give up on his date. The kind of information Masgwembe seeks from her seem unimportant and unworthy of right responses. Maswgembe's 'Ooooh!' response underlines his evident desperation in getting Msupa's attention. However, Msupa's 'Um...haha..' reaction is a clear indication of disinterest in her obviously agitated blind date. She seems to be laughing at Masgwembe which aggravates an already sour dating experience. Rygg (2012) states that every communicative situation requires us to make a choice between encouraging proximity or signal distance. The situation in the mentioned transcript encourages distance between Msupa and her blind date Masgwembe. However, Masgwembe makes incessant attempts at creating proximity which Msupa seems to thwart as demonstarated by her responses.

\subsection{Language distinction}

Bilous and Krauss (1988) ascertain that even such straightforward parameters as pitch, loudness and articulation rate are influenced by other participants' pitch, loudness and rate. It is therefore expected that the concept of convergence in such parameters would lead to closeness between interlocutors. Furthermore, language in a communicative set up may be different dependant on the social setting and the speech styles of the speaker's fellow interlocutors. In the case of this dating session between Msupa and Masgwembe, language use stands out as an indicator of the apparent social distance between them.

Masgwembe uses English, Kiswahili and a Kenyan slang language, Sheng, while Msupa sticks to English language throughout her crisp responses. For instance in Masgwembe's first verbal attempt at her date he says 'na do job kwa gym. Kulainisha hizo ma biceps na ma...' (I work in a Gym working on the biceps...) which could have been a major blunder in this dating session. Actually, Msupa did not give him time to even finish his sentence!

Masgwembe further uses Sheng in the asides with the Host: Hu hu huyu dame ananicheki faaala nini? (This lady thinks I am a low class person!) articulate his frustration at the fact that Msupa has taken him not to be of her class hence 'fala'. He further laments that 'Dame alikuwa juu ya Facebook, maTwitter, sijui WhatsApp time yote' (The lady was on Facebook, Twitter and I do not know WatsApp all the time) which shows that she did not pay any attention to her supposed date. She was more interested in the social media forums. However, Masgwembe asserts to the Host that he was not ready to give up hence the utterance 'Eeeh! Mwanaume ni kujaribu tu.' (A man must just try his luck).

From the assessments by Brown and Levinson (1987) there are grammatical differences between the speech of two or more speakers in communication which give us clues about their social backgrounds. The consistent usage of English language by Msupa and the codeswitching by Masgwembe speak large about their social orientations. The mixing of language and the usage of Sheng, points at his social class. Sheng is a Kenyan 'langauge' spoken among the supposed low class of the society. English, on the other hand, is perceived to be for the 'high' class whose image is being portrayed by Msupa. It can then be deduced that the wide disparity in language choice has created a social distance discouraging any form of convergence.

\subsection{The Asides Perspective}

This dating session was coordinated by a Host who would ask the couple their perceptions of their dates. The Host would hold private and separate sessions with each dating participant. In this case Msupa and Masgwembe were each taken through the private sessions with the Host.

\section{Transcript 4:}


ASIDE: Host to Msupa: You seemed quite preoccupied during your date with Masgwembe.

\title{
Msupa to Host: With who?
}

Host to Msupa: The guy you are on the date with.

Msupa to Host: It's just this new service from Safaricooom chat chit bundle. Lets me chat on Faceboook, Twitter and

WhatsApp for just ten bob per day.

From the transcript it can be deduced that Msupa was not interested in her date. She does not even know his name! She, however; admits that the Safaricom Chat chit bundle has preoccupied her. She is more interested in the social media due to low bundles cost than her date with Masgwembe. Her focus on the social media has created a wide social distance between herself and Masgwembe.

\section{Transcript 5:}

\author{
ASIDE: Masgwembe to Host: Hu hu huyu dame ananicheki faaala nini? (This lady thinks I am a low class person!) \\ (protesting and clearly annoyed) \\ ASIDE: Masgwembe to Host: Dame alikuwa juu ya Facebook, maTwitter, sijui WhatsApp time yote. (The lady was on \\ Facebook, Twitter and I do not know WatsApp all the time) \\ Host to Masgwembe: Would you like to see her again? \\ Masgwembe to Host: Eeeh! Mwanaume ni kujaribu tu. (A man must just try his luck)
}

Masgwembe's private sessions with the Host are full of complaints and protestations at the way his date has treated him. He has observed that the lady was more focused on the social media of which Masgwembe may not be conversant with. However, he is still determined to keep on trying his luck to win over Msupa. He tells the Host that a man must try his luck. It is clear that the disparity in their world outlook is a major undoing in their dating process. Oakes (1987) posits that an identity may become enhanced and magnified as a function of the interaction between the characteristics of the interlocutors in a communicative situation. This assertion can be related to the dating situation between Msupa and Masgwembe as each of them seems to maintain their unique characteristics. The divergence is still very clear even during their private sessions with the Host.

\section{Conclusion}

From the analysis and discussion in this article, it can be deduced that divergence and convergence can be demonstrated from different viewpoints. For instance, Masgwembe attempted to win over Msupa by showing off his perceived well toned body. His demonstration failed to impress the aloof Msupa. Such physical demonstrations are not in any way within the social media world view which Msupa believes in. Their linguistic mannerisms are equally a pointer of their incompatibility. Masgwembe uses the Sheng 'language' while Msupa sticks to English language. The former is a corrupted code of communication while the latter is usually viewed as a language of prestige. The findings in this article therefore confirm Hogg and Abrams' (1988) concept of social categories. This is in reference to the concepts of divergence and convergence as interlocuters either strive to maintain their unique identities or strive to be like the other person in diverse social settings. The dating session involving the two participants has shown how social distance can deter any relationship between characters that are worlds apart in terms of language, technology and general mannerisms. The study concludes that the influx of social media platforms seem to interfere with the traditional ways of holding a conversation. Masgwembe may be a representation of the traditional face to face interaction while Msupa stands for the new generation who would rather spend time online than engage in verbal talk.

\section{References}

Bilous, F. R., \& Krauss, R. M. (1988). Dominance and accommodation in the conversational behaviours of same- and mixed gender dyads. Language and Communication, 8, 183-194.

Bourhis, R. Y., \& Giles, H. (1977). The language of intergroup distinctiveness. In H. Giles (Ed.), Language, ethnicity and intergroup relations (pp. 119-135). London: Academic Press.

Brown, P. \& Levinson, S. C. (1987). Politeness; Some Universals in Language Usage. Cambridge: Cambridge University Press.

Bruner, J. (1990). Acts of meaning. Cambridge, MA: Harvard University Press.

Calcott, M.F. \& Lee, W. (1994). A content analysis of animation and animated spokes- characters in television commercials. Journal of Advertising, Vol. 23, No. 4 (Dec. 1994), pp. 1-12.

Dyer G., (1982). Advertising as communication. England: Clays Ltd, St. Ives PIc. 
Garretson, J.A. \& Niedrich, R.W. (2004). Spokes-characters: creating character trust and positive brand attitudes. Journal of Advertising, 33, 25-36.

Hogg, M.A. \& Abrams, D. (1988). Social identification: A social psychology of intergroup relations and group processes. London: Routledge

Krauss, R.M. \& Chiu, C. (1998). Language and social behavior. In D. Gilbert, S. Fiske \& G. Lindsey (Eds.), Handbook of Social Psychology (Vol. 2, pp. 41-48). Boston: McGraw-Hill.

Kumar, R. (2011). Research methodology: A step-by-step guide for beginners.London: SAGE.

Leiss, W., Kline, S. \& Jhally, S. (1990). Social communication in advertising: person products \& images of well-being, Second Edition. Scarborough, Ont: Nelson Canada

Levin, H. \& Lin, T. (1988). An accommodating witness. Language and Communication, 8, 195-198.

Luo, J.T., Peter M., Susan, B. \& Kathleen A. K. (2006). "On- screen characters: their design and influence on consumer trust", The Journal of Services Marketing. 53 (April), 48-65.

McDonald, C. (1992). English Language Project Work. London: Macmillan Press Ltd.

Neeley, S.M. \& Schumann, D.W. (2004). Using animated spokes-characters in advertising to young children: does increasingattention to advertising necessarily lead to product preference? Journal of Advertising, 33, 7-23.

Oakes, P. (1987). The salience of social categories. Pp. 117-47, in Rediscovering the Social Group, edited by John C. Turner. New York: Basil Blackwell.

Petty, R. E., \& Cacioppo, J. T. (1986). Communication and persuasion: Central and peripheral routes to attitude change.New York: Springer-Verlag.

Rygg, K. (2012). Direct and Indirect Communicative Styles. A Study in Sociopragmatics and Intercultural Communication. Based on Interview Discourses with Norwegian and Japanese Business Executives. PhD thesis. Bergen, Norway: University of Bergen.

Stets, J. E. \& Burke, P. J. (2000). Identity theory and social identity theory. Social Psychology Quarterly vol. 63, No. 3, $224-237$.

Stephan, E., Liberman, N. \& Trope, Y. (2010). Politeness and Psychological Distance: A Construal Level Perspective. Journal of Personality and Social Psychology 98 (2). 268-280.

Turner, J.C., Hogg, M.A., Oakes, P.J., Reicher, S.D. \& Wetherell, M.S. (1987). Rediscovering the social group: A self-categorization theory. NewYork: Basil Blackwell.

Taylor A. S. (2012). Animation as a Tool for Development Communication: An HCl Perspective. Ashesi University College. Thesis submitted to the Department of Computer Science Ashesi University College. In partial fulfillment of the requirements for the award of Bachelor of Science degree in Computer Science.

Wayne, D.G., \& Stuart, M. (2004). Research methodology: An Introduction, South Africa: Juta and company 
